\title{
LOS INICIOS DE LA RETÓRICA ARISTOTÉLICA: EL GRILO
}

\author{
María Luisa FEMENIAS \\ Universidad Nacional de La Plata \\ Universidad de Buenos Aires
}

El intento de identificar en la Retórica diversos estadios de elaboración pertenecientes, a su vez, a diferentes épocas de la vida y del pensamiento de Aristóteles ha resultado poco menos que provisorio. Düring ${ }^{1}$, por ejemplo, se inclina por sostener que toda la obra retórica del filósofo pertenece a distintos momentos del período académico. Los libros 1 y $\mathrm{ll}$, con la excepción de los capítulos 23-24 y parte del 26 (que serían una adición posterior) formarian un cuerpo unitario $y$, más propiamente, un ars rhetorica. Por su parte, el libro III, que tiene unidad propia, sería un tratado sobre la prosa. Düring conjetura, además, acerca del destino de algunos de los trabajos de retórica que enumeran tanto Diógenes Laercio como Hesiquio en sus catálogos, trabajos que, a su entender, podrían haberse preservado como partes de la Retórica, tal como la conocemos en su estado actual'.

Por su parte, Kennedy ${ }^{3}$ sugiere que aún cuando la Retórica fuera una obra temprana (seguramente el núcleo más antiguo, libros 1-11, pertenecería al periodo en que Aristóteles era todavía

'During, 1. Aristóteles, México, UNAM, 1990 (1* ed. en alemán 1966), pp. 193-255.

2 During, l. op.cit. p. 193, seguido por Viano, C. A. "Aristotele e la redenzione della retorica" Rivista di Filosofia, LVIII, 1967.4, especialmente, p. 387 nota 47.

3 Kennedy, G.A. On Rhetoric: a theory of civic discourse, Ner York, Oxford University Press, 1991, Appendix II, pp. 299-305; el estudioso remite a Grimaldi, Solmsen y Rist.

Éndoxa: Series Filosóficas, $n^{\circ} 7,1996$, UNED, Madrid:

María Luisa Femenías: Los inicios de la retórica aristotelica: El Grilo.

pp. 43-57. 
discípulo de Platón), tal como ha llegado hasta nosotros sería el producto de revisiones parciales posteriores, realizadas en el último periodo de su vida, y muy probablemente orientadas a un curso "inaugural" de retórica, a su regreso a Atenas, en el Liceo. Para ello, habria subsumido trabajos anteriores, nombrados de manera independiente en el catálogo de Diógenes Laercio. Esta hipótesis permite a Kennedy dar cuenta de las dos posibles líneas de interés de la obra. La primera en estrecha vinculación con los diálogos platónicos y, en cierto sentido, más filosófica; la segunda, por el contrario más pragmática y claramente vinculada a la función persuasiva.

En lo que sí hay acuerdo es en que el Grilo fue la primera obra escrita de Aristóteles, y que se inscribió en un debate típicamente ateniense: las virtudes, ventajas y desventajas de la retórica, vinculada por Platón al sistema democrático basado - a su juicioen la adulación y la ignorancia ${ }^{5}$. El interés de los escasos fragmentos del Grilo, con que contamos, radica en qué carácter asignó el joven discípulo a la retórica, y ello dentro del marco de debate, más amplio, sobre el platonismo aristotélico de los primeros años de su estancia en Atenas.

${ }^{4}$ La traducción de los fragmentos del Grilo que utilizo fue realizada directamente del griego y del latín por el prof. Francisco J. Olivieri de la Universidad Nacional de Mar del Plata (Argentina). Los testimonios que recoge Rose para la inclusión del diálogo, en un libro, entre los escritos aristotélicos perdidos son, en primer lugar, el de Quintiliano en Instituciones Oratorias $(=68-69$, infra), obra en doce libros muy celebrada por las gentes cultas de su época. En segundo lugar, la mención de la obra (Peri retorikés e Grilou), en el quinto lugar del catálogo transmitido por Diógenes Laercio. Figura también en un segundo catálogo (Hesychius) aunque citada como Peri Politikés e Grlou, en tres libros - y no unolo que parece un error. Por otra parte, también se encuentra en el catálogo de Tolomeo (-el-Garib). Asimismo, para otros estudiosos habría que incluir como testimonio o fragmento el texto de Dionysius Halicarnasus (De Isocr. c. $18=140$ ); para otros, como Chroust, merecerían tenerse en cuenta ciertos párrafos de la Retórica de Filodemo, que podrían corresponder al Grilo. Rose fiel a su tesis general sobre el carácter espúreo de los diálogos aristotélicos intentó mostrar que se trataba de un escrito de Teofrasto. Solsem mostró el carácter aristotélico del Grilo pero creyó que había sido escrito unos 3 o 4 años después de la muerte del joven. Berti, considera que no es necesario posponer tanto su redacción y lo ubica hacia el 36160. Cfr. Berti, op.cit. pág. 161-165; Thillet, art. cit. pág. 353.

${ }^{5}$ Cfr. Viano, op.cit. pp. 375; 380-381; Kennedy, op.cit. pp. 305; 309-312. 
Hacia el año 371 -como se sabe- se produce un acercamiento entre Atenas y Esparta, en parte a instancias de Calístrato de Aphidna $^{6}$. Finalmente, en el 369 , ambas ciudades se alian para enfrentar la hegemonia de Tebas. Jenofonte, antes desterrado por filoespartano, ahora envía sus hijos Grilo y Diodoro (educados en esa ciudad) a servir en el ejército ateniense ${ }^{7}$. Precisamente, Grilo cayó en un encuentro de caballería que precedió a la batalla de Mantinea ${ }^{8}$, luchando al lado de los espartanos, probablemente, en el verano del $362^{9}$. En esa batalla murió también Epaminondas, líder de los tebanos, dejando a su ciudad victoriosa y sin rumbo, con lo que pronto perdió la hegemonía que había ganado.

En la ocasión se compusieron numerosos elogios y oraciones fúnebres en honor a Grilo. Como los más nombrados, se recuerdan el de Isócrates y el de Aristóteles, del que sólo restan unos pocos fragmentos. Ahora bien, debemos considerar si los innumerables ${ }^{10}$ elogios a Grilo, surgieron espontáneamente o si fueron, más bien, el producto de una cierta "inspiración" común. Se conjeturaron diversas hipótesis para dar cuenta de los motivos por los que el

${ }^{6}$ Cfr. Jaeger, W. Paideia, México, F.C.E., 1967, pág. 1084; del mismo estudioso, Demóstenes, México, F.C.E., 1976, cap. 1, nota 32, págs. 247-252 y 259-60.

${ }^{7}$ Cfr. Ollier, F. "La renommée postume de Gryllos" Bulletin de L'Association Guillaume Budé, XVill (1959) 4. p. 429.

${ }^{8}$ Cfr. Ollier, ib. que se basa en D.L.; Viano, C.A. op.cit. p. 371; Para Berti, Düring, Guthrie, en cambio, Grilo muere en la batalla de Mantinea. Cfr. Berti, E. Le filosofia del primo Aristotele, Firenze, Olschki, 1963, pp. 115-116; Düring, 1. op.cit. p. 196; Guthrie, W.K.C. Aristotle: an encounter, Melbourne, Cambridge University Press, 1981, p. 66.

9 Cfr. Diógenes Laercio II. 5.; Kirchner, "Gryllos", Pauly Wissowa, Vl, 1912, col. 1899.

10 Thillet considera dudoso que hubiera sido escrito a la memoria de Grilo: Cfr. "Note sur le Gryllos, ouvrage de jeunesse d" Aristote" En: Reoue philosophique de la France et l'etranger, 82. 1957, 3. pág. 353. Diógenes Laercio Il. 6. Recuérdese, al respecto, que Espeusipo escribió también un diálogo titulado A Grilo. Cfr. D.L. IV. 4. 
joven Grilo llegó a adquirir una dimensión tal que hasta se lo equiparó a Epaminondas ${ }^{11}$.

En general, ya Diógenes Laercio sugiere que las oraciones fúnebres fueron escritas más para congraciarse con el padre que para la gloria del hijo ${ }^{12}$. En efecto, en esas circunstancias, la figura de Jenofonte adquirió, en principio, una suerte de "valor simbólico" pues, por un lado, se tornó emblemático de la reconciliación espartano-ateniense y, por otro, del padre que "ofrenda", en muerte heroica, la vida del hijo. Los encomios a Grilo podrían considerarse, entonces, una suerte de alegato indirecto en favor de Jenofonte y de su familia ante una opinión pública, probablemente, desfavorable $e^{13}$. Además, los filoespartanos atenienses deben haber encontrado en Grilo no sólo el símbolo de la unión entre las dos ciudades sino un modo no directo, aunque eficaz, de defender la política promovida por Calístrato y de ejercer cierta influencia sobre la opinión pública ateniense sobre el ideal panhelénico ${ }^{14}$.

\section{II}

Ahora bien, Isócrates, dijimos, escribió un elogio a Grilo. Para explicar sus posibles motivos. Ollier - siguiendo a Mathieu ${ }^{15}$ gusta subrayar que el pensamiento político de Jenofonte y el de Isócrates dan muestras de "influencia reciproca". Efectivamente,

${ }^{11}$ Ollier, art. cit. p. 435.

12 Diógenes Laercio, ll. 6. vi. D.L. utiliza el verbo charizesthai lo que lleva a Solmsen a conjeturar que el Grilo no fue una oración fúnebre sino un escrito destinado a polemizar con un tipo de retórica. Cfr. Berti, op.cit. pág. 163, n. 206. Viano, C. A. op.cit. p. 371. Platón utiliza ese término para subrayar el servilismo de la retórica sofística. Entre otros, cfr. Gorg. 462 c 9 , en boca de Polo "no te parece la retórica algo bello capaz de agradar (charizesthai) a los hombres ?"; 501 b 9, habla Sócrates "...ni tampoco les importa alguna otra cosa, sino sólo agradar' (charizesthai)"; $513 \mathrm{~d}$, Sócrates dice "... hay dos actividades para tratar el alma: una se asocia con el placer, pero la otra con lo mejor, no complaciendo (katachariszomenon), sino luchando.".

13 Thillet, art. cit. pág. 353; Ollier, art. cit. p. 430.

14 Viano op.cit. p. 374-375; Ollier, art. cit. p. 431

15 ibid. Cfr. también, Ollier, p. 432-433. 
ambos originarios de Erquia ${ }^{16}$, ambos hostiles a los tebanos, admiraron profundamente a Esparta (tal como el mismo Platón lo hiciera). La intención de Isócrates habría sido, entonces, elogiar a Grilo, idealizado como un personaje justo, gracias a una educación basada en el modelo espartano o, al menos, en el ateniense tradicional. Quizá, y sin desconocer otros motivos (algunos mencionados más arriba), en su elogio, Isócrates propuso a Grilo como un ejemplo para la juventud ateniense de su tiempo. Esto dio lugar, según parece, a apreciaciones polémicas y encontradas respecto de su concepción de la paideia y de la arete $e^{17}$.

En su Contra los Sofistas, Isócrates desarrolló un programa educativo, posiblemente en velada respuesta a los ataques del Gorg. platónico ${ }^{18}$. Berti sugiere que Isócrates deseó diferenciarse de los sofistas retóricos, tan duramente criticados por Platón, y salvar así su escuela. De la polémica con Platón hay huellas en el Helena, donde atacó la unidad de la virtud, de la ciencia y de la enseñanza, condenando a Platón como "erísitico", si bien le reconoce un plan educativo y una orientación política. La respuesta de Platón se oye en el Eutid. ${ }^{19}$ y la contra-respuesta en el Paneg. exhortación a la filosofía entendida como cultura general del espíritu. Nuevamente, los estudiosos reconocen en Rep. la réplica de Platón $2^{20}$. Finalmente, en Fedr., donde coinciden tanto alusio-

16 Diógenes Laercio II.1.

17 Jaeger, op.cit. 111. 2, contrapone la concepción platónica (seguida por el joven Aristóteles) de paideia y de arete a la isocrática, (p. 833) aunque le daba el nombre de "filosofía" (p. 834) no excedia de una "mera cultura política general". Cfr. también Kennedy, G. The art of persuasion in Greece, London, Routledge \& K. Paul, 1963, págs. 175-203.

18 Viano, op.cit. pp. 374-375, reseña brevemente sus alusiones recíprocas. Recuérdese, además, que Isócrates fue - según la tradición- el alumno más destacado de Gorgias.

${ }^{19}$ Eutid. 278 e-282 e, en una discusión sobre las virtudes y la buena fortuna; 304 d-306 c en referencia a "alguien muy diestro y competente en escribir discursos para los tribunales". Cfr. también pág. 268 nota 131 de Platón Dialogos II, Madrid, Gredos, 1983; Berti, op.cit. págs. 169-170.

${ }^{20}$ Rep. 500 b-c "los culpables son aquellos intrusos que han irrumpido en ella «la filosofía" de modo desordenado e indebido (....) no queda tiempo para descender 
nes adversas ${ }^{21}$ como la única mención expresa de Isócrates ${ }^{22}$, Platón, en clara confrontación con los retóricos de su época, sienta las bases para la "nueva retórica" filosófica que, eventualmente, iba a devenir en una verdadera techne.

Es cierto que Platón ṇo podía considerar a Isócrates un retórico del tipo sofístico propagador de un relativismo ético y político sin ideales. No obstante ello, las diferencias entre ambos son notables. Básicamente, Isócrates es considerado el fundador de la cultura humanística, pero debe tenerse en cuenta que el suyo fue un humanismo retóricoliterario $y$, en ese sentido, incompatible al cientificofilosófico de Platón ${ }^{23}$. El ideal educativo de Isócrates se limitó a defender una formación espiritual, cultural y retórica basada en los ideales morales tradicionales, que recogió bajo el nombre de filosofía. Sin método ni objeto propio, para Isócrates, la filosofía, de acuerdo al uso de su época, no significa más que una especie de "cultura general" basada en el conocimiento de la historia y la doctrina de las ideas (ideai), es decir, de las formas fundamentales del discurso, en el marco de una praxis política conservadora.

Este es el clima en el que Aristóteles tercia con su Grilo. Según la tradición, Isócrates habría sido atacado ásperamente por el joven académico, dispuesto a defender firmemente los ideales de su

la mirada hacia asuntos humanos y ponerse en ellos a pelear, colmado de envidia y hostilidad ..." Cfr. también, Kennedy, op.cit. págs. 17, 188 (escuelas rivales), 74 (el Fedr. como respuesta al Helena), 179 ss. (como díscípulo de Sócrates).

${ }^{21}$ Cfr. Fedr. 260 e - 262 c "En el caso, claro está, de que los argumentos que vengan en su ayuda atestigüen que «la retórica» es un arte. Porque me parece estar oyendo algunos argumentos que se adelantan y declaran en contra suya..."; 263 b; $265 \mathrm{~d}-266 \mathrm{c}$ "el arte de los discursos con los que Trasímaco y otros se hicieron ellos mismos sabios en el hablar e hicieron sabios a otros..."

22 Cfr. Fedr. 278 e -279 a “... el bello Isócrates... me parce que por sus dones naturales es mucho mejor para los discursos que Lisias, y la mezcla de su carácter es mucho más noble..." Ahora bien, si el elogio es verdadero (Willamovitz) o una ironía más de Platón (Robin, Kennedy) ha sido tema de discusión, cfr. Berti, op.cit. pág. 172-173. 203.

23 Berti, op.cit. págs. 166-172. Jaeger, op.cit. Parte lll.; Kennedy, op.cit. págs. 175- 
Escuela ${ }^{24}$. Si se admite con Berti ${ }^{25}$ y otros estudiosos, que el Fedr. fue escrito hacia el 369, Aristóteles redactó su Grilo en conocimiento de la "retórica filosófica" del Fedr. Es posible, entonces, que el Grilo se viera afectado por ambos diálogos aunque se lo hace más próximo al Gorg. ya que, en un pasaje que se conserva (infra), Aristóteles afirma que la retórica no es un arte.

\section{III}

Cuál fue, por su parte, la intención de Aristóteles al escribir él también un encomio al joven Grilo? Ollier cree que, siendo Isócrates un perfeccionista, habria pulido su obra hasta considerarla perfecta, publicándola, en consecuencia, en último término ${ }^{26}$. En cambio, Berti -siguiendo en esto a Somsen y con la coincidencia de todos los estudiosos- sostiene convincentemente que Aristóteles escribió el diálogo $\mathrm{Grilo}^{27}$, quizá su primera composición literaria ${ }^{28}$, cuando sólo llevaba 6 ó 7 años en la Academia y no tenía más de 25 o 26 años. El nombre "Grilo" habria sido utilizado como pretesto para cuestionar una cierta retórica.

Platón; tras su regreso de Siracusa, fracasado el proyecto político que lo había llevado hasta allí, se habría avocado de pleno

24 Este podría ser el sentido de la afirmación de Dioniso de Halicarnaso de que Aristóteles afirmaba que los discursos de oratoria forense de Isócrates se vendian en el mercado. Cfr. p.e. Bernays, J. Die Dialoge des Aristóteles, 1968. p. 157.

25 Berti, op.cit. pág. 173. Guthrie, op.cit. conjetura que lo escribió hacia el 360 o poco despues, pp. 6 nota 3.

${ }^{26}$ Cfr. Ollier, art. cit. p. 432 . Esta conjetura no es retomada por Düring.

27 Respecto de si la obra fue escrita en forma de diálogo o no, existen ciertas dudas. Tienden a creer que lo fue: Berti, op. cit. p. 116; 165-166. Düring, (op. cit., p. 205, pass., más cautamente, en p. 196 "probablemente un didlogo") y Ollier (art.cit.p. 433) sostienen que no hay certeza de que lo fuera: Thillet, F. (art. cit. pág. 353), prefiere hablar de "una obra" sobre retórica; Guthrie (op. cit., p. 66). Q. Racionerosiguiendo a Jaeger- afirma que se trató de un diálogo cuyo modelo fue el Gorgias. CFr. Retórica, Madrid, Gredos, 1990, Introducción, pág. 19.

${ }^{28}$ Chroust, A.H. "Aristotle's first literary efford: the Gryllus", Reoue des études grecques, LXXVlll, 1965, p. 576 s.; Viano, C.A. op. cit. p. 371. Berti, op. cit. pp. 115. 160-1 siguiendo el listado que transcribe Moreaux en Les listes anciennes des ouvrages $d^{\prime}$ Aristote, Louvain, P.U. de L. 1951; también Guthrie, op. cit. p. 66. 
a su trabajo en la Academia, creando de ese modo - a juicio de Berti- un clima de fuerte entusiasmo, del que el joven Aristóteles no fue ajeno. Un fuerte compromiso con los ideales educativos de la Escuela lo habrían llevado a defender en el Grilo un sistema contrapuesto al de la sofística en general y al de Isócrates en particular $^{29}$. El Grilo, entonces, habría sido una respuesta al homonimo elogio oratorio isocrático, el encomio. El "encomio", nuevo género literario teorizado en el Evágoras, constituía una original unión entre la forma poética tradicional y una suerte de meditación sobre los sucesos políticos actuales, dirigido a los gobernantes ${ }^{30}$. Para Platón, se trata de poner la retórica irresponsablemente al servicio no de la verdad, sino de cosas bellas y grandilocuentes (Banq. $198 \mathrm{~d}$ - 199 b), en una suerte de adulación, elogio o alabanza a los políticos que sólo buscan prosperidad económica descuidando la ciencia ${ }^{31}$.

En esta suerte de polémica sobre la retórica el Grilo de Aristóteles habría sido, a su vez, respondido por Cefisodoro, el discípulo más fiel de Isócrates, de quien, al decir de Düring, el filósofo haría una encubierta referencia en Ret. ${ }^{32}$. Según Berti, Cefisodoro, en su Contra Aristóteles, criticó al estagirita y, considerándolo un platónico más, atacó la teoría de las Ideas ${ }^{33}$.

29 Berti, op. cit, pág. 160.

${ }^{30}$ Jaeger, op. cit. págs 871-872; Viano, C.A. op. cit. p. 372 y ss, donde analiza la concepción adulatoria de la retórica en los principales diálogos de Platón especialmente en Gorg. Banq. Menx.; Berti, op. cit. pág. 164 n. 212; 165.'

31 Viano, op. cit. p. 373; 375.

32 Ret. 1379 a 32-36 El pasaje no da nombres y no es para nada claro que se esté refiriendo a Cefisodoro o a la escuela de Isócrates.

33 Berti, op. cit. págs. 183-185. Ahora bien, por qué para atacar a Aristóteles Cefisodoro critica la doctrina de las Ideas? Berti recoge varias posibles respuestas. Bernays (1863) sugiere que Cefisodoro ataca a Aristóteles intentando atacar a Platón. Jaeger (1923), y Bignone (1936) consideran que Cefisodoro ataca a Aristóteles porque, al igual que Platón, sostenía por esa época la teoria de las Ideas. Düring (1966) sigue a Numenio (ll d.c.) y sugiere que "puertas afuera" de la Academia no se distinguían bien sus líneas internas; por tanto, las polémicas entre el Maestro y el joven discípulo eran sólo cuestión de "intramuros". Cfr. También Chroust, "Aristotle's earliest course of 'Lectures on Rhetoric" L'antiquite classique, 33, 1964. 59. pág. 70 nota 60; Viano, op. cit. p. 374, sigue a Berti. 
La tradición también vincula al Grilo con un Curso de retóri$\mathrm{ca}^{34}$ que el joven Aristóteles habría dictado por ese entonces, 0 poco después, en la Academia (probablemente entre los años 360$355)^{35}$, renovando así su polémica con Isócrates. Dicho curso habría concitado el interés de los atenienses al punto de suscitar recelos en el viejo rétor, lo que habría contribuido a hacer de Aristóteles su más destacado adversario ${ }^{36}$. Diógenes Laercio recoge una tradición que hace decir al joven filósofo al inicio de sus clases "es indecoroso, si Jenócrates [= Isócrates] habla, que yo calle" ${ }^{37}$. Por su parte, los numerosos ataques de Isócrates a "ciertos sofistas" deben ser entendidos como dirigidos a Aristóteles ${ }^{38}$. Entonces, la publicación del Grilo lejos de dar por finalizada la polémica, en cierto sentido, la incentivó ${ }^{39}$.

\section{IV}

Luego, según parece, el Grilo trata con espíritu polémico, en general, de la retórica contemporánea $y$, en particular, de la isocrática. Así, se nos transmite con el subtítulo Sobre la Retórica.

${ }^{34}$ La referencia se encuentra en el De Rhetorica 11.50 de Philodemo. Hay una importante controversia sobre si la Retórica recoge o no las notas de este curso y cual es su vinculación con la Retórica a Teodecto. Ctr. Chroust, art. cit.; Viano, op. cit. p. 377 especialmente nota 19; Berti, op. cit. 175-185, especialmente págs. 182 (conclusiones de Berti) y 522. Kennedy, op. cit. Apéndice II. b-c.

35 Chroust, art. cit. pág. 72; Berti, op. cit. pág. 175.

${ }^{36}$ Jaeger, op. cit. III. 2; Düring, op. cit. p. 196; A. Tovar, en la Introducción a su traducción de la Retórica, Madrid, Estudios Constitucionales, 1985, pág. XXVIII. Q. Racionero, en la Introducción a su traducción de la Retórica, Madrid, Gredos, 1990. págs. 59-67.

${ }^{37}$ Diógenes Laercio V.2. Todos los estudiosos coinciden en que debe leerse Isócrates. En contraste, cfr. las refencias positivas de Ret. 1392 b 11;1408 b 15; 1414 b 33; 1418 a $31 ; 1418$ a 34 y 1418 b 26. Cfr. también Düring, op. cit. pág. 249; Berti, op. cit. 183 nota 305.

38 Tovar, op. cit. pág. xxviii.

${ }^{39}$ Chroust, A-H. Aristotle' Protrepticus: A reconstruction, Notre Dame University Press, 1964, págs. X-XII.; Chroust supone que A Demonico de Isócrates es una respuesta al Protep. aunque las semejanzas y conexiones entre el Protrep. y la Antidosis de Isócrates no permiten saber cuál es respuesta de cuál. 
Solmsen fue el primero en recoger el carácter polémico de la obra, siguiendo algunos indicios del contexto quintiliano ${ }^{40}$. Jaeger ${ }^{41}$, por su parte, consideró que el Grilo responde al Gorgias como el Eudemo al Fedón: "no pueden haber sido muy distintos del primer tipo platónico, del que son ejemplos el Fed. y el Gorg.", afirma. De este modo refuerza su posición respecto de un platonismo a-crítico en el primer Aristóteles. Del mismo modo, Thillet ${ }^{42}$ cree que el pensa- $^{2}$ miento aristotélico depende aún del platónico y, por tanto, el Grilo retomaría la línea de pensamiento del Gorg. y del Fedr. respecto del papel de la retórica. También Racionero ${ }^{33}$-siguiendo fielmente a Jaeger y Solmsen-considera que el Grilo reproduce las tesis del Gorg. acerca del carácter meramente adulador de la retórica.

El análisis de Aristóteles no podría ser en este punto muy distinto del de Platón, se afirma: sin un fundamento filosófico, la retórica se torna persuasión en la mera creencia (Gorg. 454 e). No es suficiente con que un orador pase por tener ciertos conocimientos, debe, en verdad, poseerlos ( 459 d). En el diálogo, la concesión de Gorgias a Sócrates motiva, como se sabe, la airada intervención de Polo (461 b-480 e) que no logra siquiera atisbar el planteo socrático, siendo reemplazado en la indagación, a su vez, por Calicles. En fin, sin filosofía el objetivo de la retórica se agota en obtener el beneplácito del auditorio sustituyendo el conocimiento de la verdad y del bien por meras apariencias, pues el ejercicio retórico incluso se sustraería a las reglas morales ${ }^{44}$.

\footnotetext{
${ }^{40}$ Cfr. Thillet, op. cit. pág. 353; Viano, op. cit. pág. 375; Berti, op. cit. pág. 162.

41 Jaeger, W. Aristóteles, México, F.C.E. 1992; págs. 41-42, seguido por casi todos los estudiosos.

42 Thillet sugiere que sus argumentaciones eran de tipo platónico, op. cit. pág. 353; Viano, op. cit. p. 374; Ollier, op. cit. p. 433.

${ }^{43}$ Cfr. Jaeger, Paideia..., p. 877; Viano, op. cit. p. 371 ss. cita a Solmsen en italiano; Racionero, op. cit. Introducción, pág. 23.

44 Thillet recoge las afirmaciones de Quintiliano en Inst. Orat. 11.17. 30, la retórica a la que se referiría Aristóteles no tendría en cuenta los pros y los contras, es decir, sería indiferente al bien y al mal y, en consecuencia, ajena a la filosofía, op.cit. 354 . Racionero, siguiendo a Solmsen, op.cit. Introducción, pág. 23.
} 
Ahora bien, Quintiliano (Inst. Orat. 11.17) ${ }^{45}$ transmite la noticia de que Aristóteles negaba que la retórica fuera un arte (non artem) conclusión que cree paradójica e insostenible a la luz de las afirmaciones del filósofo en su Ret. $^{46}$, y por tanto, tilda al Grilo de mero ejercicio argumentativo. Según Berti, Bernays es el primero en reparar en esta contradicción, aunque su solución no le satisface $^{47}$ pues apela a la división de los escritos de Aristóteles entre esotéricos y exotéricos. Las traducciones modernas recogen fielmente la afirmación "la retórica no es un arte" 48 con la excepción de un curioso pasaje de Guthrie ${ }^{49}$ sobre el que volveré más adelante.

La cuestión de si la retórica es o no un arte, lejos de ser trivial, permite hacer algunas consideraciones en referencia a la génesis y el desarrollo del pensamiento aristotélico. Thillet ${ }^{50}$ conjetura que sólo es.posible explicar la contradicción del joven profesor de retórica escribiendo contra la retórica si se trata, en cada caso, de concepciones diferentes. En un sentido, "retórica" sería asimilable a un conjunto de reglas empíricas sin fundamento en la verdad y en la justicia mientras que, en el otro, por el contrario, estaria basada en la filosofía. De este modo, acerca el Grilo al Fedr.. Esta maniobra es

45 Rose, V. Aristoteles Fragmenta, Stuttgard, Teubner (1886), 1967.

46 Cfr. Ret. 1354 a 11-12, donde Aristóteles afirma que la retórica es un arte (techne... einai); Ollier, op. cit. pág. 433 . Viano, op. cit. , p. 371 s.; Berti, op. cit. págs. 160-162.

47 Berti, op. cit. pág. 162 n. 203. Bernays apela a la división entre escritos esotéricos y exotéricos. El Grilo representaria a los segundos y Ret. a los primeros. Para Berti, esta solución se apoyaría sobre bases artificiosas.

48 Cfr. Ollier, op. cit , pág. 433; Giannantoni, G. Opere, Roma-Bari, Laterza, 1984, pág. 101; Barnes, The Complete Works of Aristotle, New Jersey, Princeton University Press, 1984, vol. li, pág. 2418; Berti, op. cit. págs. 160; 161; 162.

49 Cfr. Guthrie, op. cit. pág. 66, "..he not only admited rhetoric to be an art, but allowed it a small share in the arts of politics and dialectic" y más adelante, "...< he> 80 his own way and take Plato up on his denial that rhetoric was an art." El mismo Guthrie señala su divergencia con Berti (cfr. n. 3 y 4 ), quien se apoya en Plinio (Plinio, Hist. Nat. XXXV1. 30). Cfr. op. cit. en pág. 181 nota 299. Cfr. Chroust, art. cit. pág. 67.

${ }^{50} \mathrm{Cfr}$. Thillet, op. cit. 354. 
seguida por Chroust ${ }^{51}$, quien además vincula al Grilo con el famoso Curso de retórica en el que Aristóteles habría enseñado su "nueva dialéctica" o forma de "argumentación científica". Ahora bien, en Fedr. 268 a ss, y especialmente a partir de 269 d, Sócrates defiende un arte retórico y persuasivo que se alcanza, no por el camino de Lisias y Trasímaco, sino por el dominio de una téchne que (270 b) analoga al conocimiento médico. La presentación de esta téchne le habría valido a Aristóteles el enconado enfrentamiento con Isócrates.

Ahora bien, si el joven filósofo afirmó que la retórica no es un arte (en el sentido aceptado por los rétores de la época), el trabajo estaría más próximo al Gorg. que al Fedr. ${ }^{52}$; reforzándose, de ese modo, la tesis jaegeriana del platonismo del joven discípulo. Justamente, en Gorg. 462 b, Sócrates, que interroga ahora a Polo, debe él mismo responder a la pregunta de éste sobre si la retórica es o no un arte:

Sócr.: Preguntas acaso qué arte (techne) afirmo yo que es?

Polo: Yo si

Sócr.: A mi, por lo menos me parece que ninguno, Polo, para decirte la verdad.

Por tanto, si en su primera obra Aristóteles adhirió a esta tesis, deberíamos preguntarnos por el momento en que se produjo el punto de inflexión a partir del cuál su pensamiento se orientó hacia la posición de Ret., donde sostions que la retórica es, efectivamente, una téchne. Sería necesario también determinar el papel que el Fedr. pudo haber jugado en ello.

En este sentido, Viano ${ }^{53}$ sostiene que la reelaboración aristotélica del carácter de la retórica debe situarse en el marco general de la crisis de la dialéctica tal como Platón la entendió, por lo menos, hasta el Fedr. El diálogo perdido Sofista, homónimo al platónico y probablemente posterior a él, marcaría el momento de transición.

\footnotetext{
51 Cfr. Chroust, op. cit. pág. 71-72.

52 Cfr. Gorg. $463 \mathrm{~d}$ (politikes... eidolon); 465 a (techne ... ou einai).

53 Viano, op. cit. pp. 378 especialmente nota 22 y sigs.
} 
El estudioso se basa en Siriano quien relata que Aristóteles enseñó que dialéctica y retórica son ambas "artes de persuadir". La conclusión de Viano es que Aristóteles osó colocar dialéctica y retórica en un mismo plano, y quizá, incluso entendió a la filosofía platónica como un gran intento persuasivo; afirmación que me parece altamente arriesgada. Sea como fuere, el Sofista aristotélico, producto de la crisis de la dialéctica del maestro, habría llegado a considerar a la retórica un instrumento del político, medio gracias al cual lograría influir persuasivamente sobre el alma, marcando de ese modo el gozne sobre el que giraría más adelante su concepción de la retórica.

Por tanto, a mi modo de ver, habría que tener en cuenta un inçipiente desarrollo de la teoría política de Aristóteles y desde un punto de vista conceptual, al menos, la clara diferenciación entre (a) un conjunto de habilidades más o menos claras (sedimentadas por la experiencia de los rétores) que llevaran a la persuasión y (b) el contenido o conjunto de "verdades" en las que se debía persuadir (producto del examen y de la investigación filosóficos). En este caso, la estrategia aristotélica parece haber sido aceptar los aportes de la retórica de su tiempo sin dejar de lado los objetivos políticopedagógicos de Platón, a partir de este hallazgo habria desarrollado, más adelante, su técnica retórica.

Pero, para la época en que Aristóteles escribió el Grilo se considera válido el testimonio de Quintiliano sobre la proximidad de Aristóteles al Maestro. Con todo, se sugiere que Aristóteles ${ }^{54}$ debe haber tomado sus argumentos del Gorg. con el agregado algunos propios, demostrando al hacerlo gran habilidad. Siguiendo nuevamente a Quintiliano, Thillet ${ }^{55}$ reconoce en el Grilo cuatro núcleos temáticos:

${ }^{54}$ Cfr. Thillet, op. cit. 353-354; Berti, op. cit, pág. 164.

55 Cfr. Thillet, op. cit. 353-354, sugiere que Quint. podria haber inventado los argumentos, aunque subraya su tono platónico. Quint. Inst. Orat. II.17; 18; 22; 30, respectivamente, y supra, nota 37. 
1. la retórica no tiene un objeto propio (Cfr. Gorg. 451 a-d),

2. la retórica es una mimesis, y es condenable en tanto tal,

3. la retórica no es un arte porque no posee fin propio,

4. la retórica defiende argumentativamente tanto la tesis como la antítesis.

Ahora bien, más arriba adelanté que Guthrie hace una lectura diferente del pasaje de Quintiliano y llega, por tanto, a otra interpretación. En efecto, Guthrie considera que "la retórica es una téchne". Si su lectura fuera correcta, mostraría que Aristóteles ya se había diferenciado del modelo teórico platónico a poco de haber ingresado en la Academia y en la primera obra que trasciende los muros de la Escuela. La ventaja de esta suposición es que, entonces, no habría contradicción entre el Grilo y la Ret., pero debería aceptarse un distanciamiento inmediato del joven discípulo de las teoría del maestro. Lamentablemente, Guthrie no se extiende sobre esta cuestión y dadas las fuentes de que disponemos, sus conclusiones resultan débiles ${ }^{56}$.

La posición de Berti me parece, entonces, la más prudente: aceptar aquella interpretación que mejor armonice con los datos que conocemos. Si es así, en el Grilo, Aristóteles habría negado el carácter de techne de la retórica, porque sólo dirigiría el alma por medio de elementos irracionales. Para ser verdaderamente una técnica debería fundarse -como afirmó Platón- en la filosofía y, es aquí donde la concepción filosófica de Platón y de Isócrates colisionan (supra). En consonancia con los ideales académicos, el Grilo no habría sido, entonces, un mero encomio sino una clara defensa de la filosofía en su sentido más estricto. No se trataría, por tanto, de una oración fúnebre ni tampoco de un elogio póstumo, sino, seguramente, del cuestionamiento a un cierto tipo de retórica y de una discusión sobre si constituia efectivamente o llegaba a constituir una techne o no, en abierta polémica con la Escuela de Isócrates ${ }^{57}$.

\footnotetext{
${ }^{56}$ Cfr. Guthrie, op. cit. pág. 66.

57 Thillet, art. cit. pág. 353; Berti, op. cit. pág 165.
} 


\section{Bibliografia}

BERNAYS, J. Die Dialoge des Aristoteles (1863) 1968.

BERTI, E. La filosofia del primo Aristotele, Firenze, Olschki, 1962.

Chroust, A-H. Aristotle, London, Routledge \& Kegan Paul, 1973. Vol. II. pp.1-2, 29-42.

-"Aristotle's earliest course of "Lecture on rhetoric", L'antiquité classique 33. $1964,59$.

-"Aristotle's first literary efford: the Gryllus", Reoue des

etudes grecques, LXXVlil, 1965.

GUTHRIE, W.K.C. Aristotle: an encounter, Australia, Cambridge

University Press, 1981.

JAEGER, W. Aristóteles (1923), México, F.C.E. 1992.

KIRCHNER, R.E. "Gryllos" En: Pauly Wissowa, VIl, 1912, col. 1899.

LOSSAU, M. "Der Aristotelische Gryllos Antologisch", Philologus, 118 (1974),12-21.

OLLIER, F. "La renommée posthume de Gryllos, fils de Xénophon", Bulletin de la Association G. Budé (1959) 425-437.

RACIONERO, Q. "Introducción". En: Retorica, Madrid, Gredos, 1990.

SOLMSEN, F. Die Entwicklung der aristotelische Logic und Rhetorik, Berlin, 1929, p. 196$207,250$.

THILLET, F. "Notes sur le Gryllos, ouvrage de jeneusse d'Aristote", Reoue de lo France et de l'étrangere, 82 (1957), 352-354.

TOVAR, A. "Introducción". En: Retórica, Madrid, Estudios Constitucionales, 1986.Viano, C. A. "Aristotele e la redenzione della retorica", Rivista di Filosofia, LVIII, 1967. 4. 